\title{
O INTELECTUAL EDUCADOR MANOEL BOMFIM E A INTERPRETAÇÃO DO BRASIL E DA AMÉRICA LATINA
}

\author{
Sônia Camara* \\ UERJ-FFP \\ soniacamara@uol.com.br \\ Marcela Cockell ${ }^{* *}$ \\ UERJ-FFP \\ marcelacockell@hotmail.com
}

\section{RESUMO}

Este artigo tem como objetivo historicizar na produção intelectual do educador Manoel Bomfim (1868-1932), o livro A América Latina: males de origem, publicado em 1905, identificando as suas contribuições teóricas e interpretações acerca dos fatores socioculturais que ajudavam a explicar a sociedade brasileira. No contrapelo com as concepções racistas dominantes à época, Manoel Bomfim defendia que os males que nos afligiam não eram reflexos de nossa composição étnica, climática ou de uma suposta inferioridade racial. Para o Brasil se tornar um país democrático e progressista era necessário investir na educação, desmitificando os ideais darwinistas de seleção natural e de superioridade da raça presentes entre os intelectuais contemporâneos. Interessa-nos pensar o livro e as ideias desse educador que, comprometido com um projeto civilizador para o Brasil, não descuidou de pensar os males que assolavam o país no período da Belle Époque tropical de 1898 a 1914.

Palavras-chave: Manoel Bomfim; A América Latina: males de origem; fatores socioculturais; educação; Belle Époque tropical.

\section{THE INTELLECTUAL AND EDUCATOR MANOEL BOMFIM AND THE INTERPRETATION OF BRAZIL AND LATIN AMERICA}

\begin{abstract}
This article aims to historicize the intellectual production of the educator Manoel Bomfim (1868-1932), the book A América Latina: males de origem, published in 1905, identifying its theoretical contributions and interpretations about the sociocultural factors that tried to explain the Brazilian society. In sharp contrast with the dominant racist point during that time, Manoel Bomfim argued that our ills were not reflections of our ethnic composition, climate or a supposed racial inferiority. To Brazil to become a democratic and progressive nation was necessary an investiment in education, demystifying the darwinistic ideals of natural selection and racial superiority assumed by the contemporary intellectuals. Furthermore our interest is to reflect the book and the ideas of educator, which committed to civilizing project in Brazil, did not neglecting to think about the ills that plagued the country during the Belle Époque tropical from 1898 to 1914.

Keywords: Manoel Bomfim; A América Latina: males de origem; sociocultural factors; education; Belle Époque tropical.
\end{abstract}




\section{INTRODUÇÃO}

Este livro deriva diretamente do amor de um brasileiro pelo Brasil, da solicitude de um americano pela América. Começou no momento indeterminado em que nasceram esses sentimentos; exprime um pouco o desejo de ver esta pátria feliz, próspera, adiantada e livre. Foram esses sentimentos que me arrastaram o espírito para refletir sobre essas coisas, e o fizeram trabalhar essas idéias - o desejo vivo de conhecer os motivos dos males de que nos queixamos todos. Desse modo, as notações, as analogias, as observações, as reflexões se acumulam (Bomfim, 2002, p. 630).

Com estas palavras, Manoel Bomfim inicia o livro A América Latina: males de origem, escrito em Paris no ano de 1903 e, publicado no Brasil, dois anos depois. Fruto do seu amor pelo Brasil e pela América, o livro traz como desejo mobilizador a intenção de alcançar "a verdade", "a causa efetiva desses males, dentro dos quais somos todos infelizes" (Bomfim, ibidem, p. 631). Refletir acerca das contribuições teóricas para se constituir interpretações que ajudassem a explicar a sociedade, superando as "visões" preconcebidas acerca do país e dos brasileiros, colocou Bomfim no cenário intelectual da época no contrapelo com as concepções racistas dominantes à época.

Nesta direção, afiança Sussekind (2002, p. 620-621) que seus escritos o colocaram num movimento de superação de dicotomias, de oposições que, em grande medida, caracterizava as reflexões latino-americanas. Manoel Bomfim se apresentou como um escritor marcado por uma "dramatização discursiva" que nos faz ver e pensar o Brasil a partir de outras matrizes pouco comuns, à época, a exemplo da metáfora parasitária. Em sua interpretação, os males que nos afligiam não eram reflexos de nossa composição étnica, climática ou de uma suposta inferioridade racial, mas sim do parasitismo das metrópoles sobre a "História das nacionalidades sul-americanas" (Bomfim, 2002, p. 788). Associado a este aspecto compreendia ser necessário analisarmos outros elementos que concorriam para a formação do "caráter desses povos", como a educação. Assim, para o Brasil se tornar um país democrático e progressista, acreditava ser necessário investir na educação, desmitificando os ideais darwinistas de seleção natural e superioridade da raça presentes entre os intelectuais contemporâneos.

Partindo desta compreensão, este artigo tem como intenção historicizar a produção intelectual do educador Manoel Bomfim, com ênfase no livro A América Latina: males de origem, no conjunto de sua obra, buscando refletir acerca de suas ideias no contexto do que se caracterizou como a Belle Époque tropical de 1898 a 1914. O livro associa-se a tríade produzida posteriormente pelo autor, em que procurou refletir sobre o país articulando-o a complexa rede que o alinhavava aos demais países da América Latina.

A tríade composta por $O$ Brasil na América (1929), O Brasil na história (1930) e $O$ Brasil Nação (1931) compõe a base da reflexão e das críticas formuladas pelo autor ao pensamento da época que pregava a suposta inferioridade cultural, social e econômica dos latino-americanos. Sabemos da complexidade de sua obra e do vigor crítico que carrega, dessa forma, nossa tentativa de análise se organiza no sentido de pensar o livro como parte da preocupação interpretativa construída por Bomfim, em duas direções: a primeira a de sumarizar alguns pontos pertinentes sobre o livro e o autor tencionando problematizar o 
que consideramos estar na essência do que identificou como sendo os males de origem; a segunda a de indicar as formas como Bomfim procurou responder a essas questões.

\section{O intelectual Manoel Bomfim e os males de origem do Brasil}

Sergipano da cidade de Aracaju, Manoel Bomfim contrariou seu pai e trocou o engenho da família pelo curso de medicina. Aos dezessete anos mudou-se para a Bahia, com o objetivo de iniciar o curso. Por insatisfação com a formação oferecida na Faculdade de Medicina da Bahia, transfere-se para o Rio de Janeiro concluindo o curso na Faculdade de Medicina do Rio de Janeiro no ano de 1890. A mudança para a Capital do país, associada à rede de relações pessoais estabelecidas lançam Bomfim, definitivamente, rumo a desafios que jamais o trariam de volta à casa paterna. A amizade e os laços de identidade construídos com Olavo Bilac e Alcindo Guanabara possibilitaram a Bomfim ensejar investidas profissionais em campos de conhecimento que não se limitaram a atuação médica.

Em 1891, um ano após o termino do curso, foi nomeado médico da Secretaria de Polícia, tornando-se tenente-cirurgião da Brigada Policial do Distrito Federal. Neste mesmo ano, casou-se com Natividade Aurora de Oliveira, ano em que o país vivia a crise do encilhamento. O cenário político marcado pela renúncia de Deodoro da Fonseca da Presidência da República e a posse de Floriano Peixoto levantou discussões e controversas quanto à legitimidade constitucional do ato. As divergências acirravam as divergências entre políticos e intelectuais que defendiam e se opunham a Floriano Peixoto. A oposição foi presa e, em alguns casos deportada. Manoel Bomfim e Olavo Bilac se incluíam no grupo de oposição. Bilac foi preso e, rumores foram levantados quanto a sua suposta prisão. Em meio a este clima de insegurança, Bomfim mudou-se para Mococa, interior de São Paulo, com Natividade e sua filha Maria temendo pela segurança de sua família. Durante sua estadia na cidade dedicou-se, exclusivamente, à clínica médica. Enquanto esteve em São Paulo em seu exílio, Bomfim não publicou artigos ou qualquer outro escrito (Cockell, 2010, p. 22).

Para Aguiar (2000, p. 151) a morte da filha foi crucial no processo de desilusão que vivenciou com a medicina. Após esse acontecimento, regressou ao Rio de Janeiro, e passou a se dedicar aos estudos sociais e a educação escrevendo artigos para jornais, ministrando aulas particulares de Português, Ciências e História Natural e atuando como revisor de provas tipográficas. No entanto, foi o seu ingresso no Pedagogium que se constituiu de suma importância para a visão que iria desenvolver acerca das questões relacionadas à educação. Apresentado pelo amigo Alcindo Guanabara ao Prefeito do Distrito Federal, Furquim Werneck de Almeida foi nomeado, por ele, subdiretor da instituição, em 1897, momento em que essa já estava sob a competência administrativa da municipalidade. Em 1906, na gestão do Prefeito Pereira Passos, assumiu sua direção permanecendo até 1919, quando de sua extinção. O Pedagogium configurou-se como centro impulsionador de reformas da instrução nacional e como espaço direcionado a promover a formação do professorado das escolas públicas e privadas, oferecendo-lhes acesso aos métodos e materiais de ensino mais aperfeiçoados a partir da década de noventa do século XIX. Sobre a batuta do Pedagogium foi organizada a Revista Pedagógica, exposições e conferências direcionadas a instrução (Camara; Barros, 2006, p. 283).

Nesse ponto, no que diz respeito às iniciativas organizacionais da instrução pública no Distrito Federal, foi aprovado, pelo decreto federal 
de 1890, o Regulamento da Instrução Primária e Secundária, que entrou em vigência a partir da Lei $n^{\circ} 85$ de 1892; paralelamente, em setembro do mesmo ano, foi aprovada a sua primeira Lei Orgânica, o que implicou a criação do Conselho Municipal e de um corpo de intendentes, passando, por conseguinte, o Poder Executivo a ser exercido por um prefeito municipal nomeado pelo Presidente da República. A nova organização administrativa e política do Rio de Janeiro ensejou a implementação de relações de poder que se refletiram nas diferentes instâncias da administração pública, cabendo à municipalidade, a partir de então, gerir e orientar as propostas com relação ao atendimento da população (ibidem).

Bomfim foi diretor do Pedagogium por dezessete anos, de 1896 a 1905 e de 1911 a 1919 quando a instituição foi extinta pelo prefeito Paulo de Frontin. Neste intervalo entre 1905 e 1911 executou outras funções, dentre elas a de diretor da Instrução Pública em 1906 e a de Deputado Federal por Sergipe em 1907. Contudo, seu afastamento nunca foi, de fato por completo, pois no ano de 1906 inaugurou na instituição o primeiro laboratório de psicologia experimental, que estreitou os contatos entre a instituição e os cientistas europeus. Em Pensar e Dizer Bomfim faz uma breve referência ao laboratório:

Durante doze anos tive à minha disposição um laboratório de psicologia; nas pastas, ainda estão acumuladas anotações, traçados, fileiras de cifres... e nunca tive coragem para organizar uma parte qualquer desses dados e de os publicar, porque nunca obtive uma elucidação satisfatória. Afigurava-se me um problema aparentemente simples. Efeitos de sugestão sobre o esforço muscular; realizava uma série de experimentações e delas resultavam, ao lado de escassas indicações positivas, novos aspectos de pesquisas, isto é, novos problemas (Bomfim, 1923, p. 27).

A partir de sua atuação no Pedagogium, Manoel Bomfim passa a explorar, em seus textos, questões como: a valorização do ensino público, sobretudo da escola primária como direito de todos e dever do Estado; a preocupação com a formação de professores; a necessidade do estudo da Pedagogia como uma ciência teórica e prática, entre outros temas que elege como essenciais para se atuar sobre a situação educacional do país. Empenhou-se em construir uma linguagem que pudesse ser compreendida por todos, uma vez que compreendia ser a educação uma ferramenta essencial para o progresso.

Vale ressaltar o momento histórico em que Bomfim estava inserido, bem como os aspectos que colaboraram na organização e formulação de sua análise. Segundo Needel (1999, p.39), o período de 1898 a 1914 caracterizou-se como a Belle Époque carioca, constituindo-se como uma importante fase na história cultural brasileira. A cultura da modernidade predominante neste período era eminentemente urbana, sendo a cidade tema e sujeito das manifestações culturais e artísticas. A cidade era o lugar da construção da modernidade, e a metrópole a forma mais específica de realização da vida moderna. Quanto ao período que se descortinou a partir dos finais do século XIX, Sevcenko, afiança que:

No afã do esforço modernizador, as novas elites se empenhavam em reduzir a complexa realidade social brasileira, singularizada pelas mazelas herdadas do colonialismo e da escravidão, ao ajustamento em conformidade com padrões abstratos de gestão social de modelos europeus ou norte-americanos. Fossem esses os modelos da missão 
civilizadora das culturas da Europa do Norte, do urbanismo científico, da opinião pública esclarecida e participativa ou da crença resignada da infalibilidade do progresso. Era como se a instauração do novo regime implicasse pelo mesmo ato o cancelamento de toda a herança do passado histórico do país e pela mera reforma institucional ele tivesse fixado um nexo co-extensivo com a cultura e a sociedade das potências industrializadas. A compreensão dos fenômenos do subdesenvolvimento e das desigualdades inerentes ao sistema de trocas no mercado internacional levou um longo tempo para germinar e adquirir uma significativa substância crítica entre as elites republicanas. E enquanto essa consciência crítica não amadurecia, prevaleceu o sentimento de vergonha, desprezo e ojeriza em relação ao passado, aos grupos sociais e rituais da cultura que evocassem hábitos de um tempo que se julgava para sempre e felizmente superado (Sevcenko, 1998, p. 27).

O Rio de Janeiro, então Capital Federal, era um símbolo da República próspera, e da brasilidade e, como tal deveria apresentar-se no contexto nacional e internacional, no início do século XX. Organizada a partir de novos valores culturais, econômicos e higiênicos que passaram a ganhar força na sociedade brasileira, a cidade-capital, sobretudo na gestão do Prefeito Pereira Passos (1902-1906), associou-se a múltiplos agentes modeladores do espaço urbano e das relações sociais. Sob a influência do modelo francês de Haussmann ${ }^{1}$, o gestor da Paris burguesa e monumental surgida entre 1853 e 1870, a cidade-capital brasileira configurou-se como a forma mais específica de realização da vida moderna do país. Bomfim foi um espectador deste processo de civilização brasileira, identificada com uma matriz francesa. Em 1902, viajou para Paris em Comissão pedagógica do governo brasileiro para estudar psicologia experimental, sendo aluno de Alfred Binet e George Dumas. O contato com o modelo de modernidade francês e a vivência do processo que se vinha desenhando no Brasil, desde finais do século XIX, ampliou a sua visão sobre o Brasil e as questões socioculturais. Desta forma, o projeto de escrever A América Latina: males de origem foi efetivado em terras francesas no ano de 1903 (Cockell, 2010, p. 24).

Publicado pela primeira vez, no Brasil, em 1905 pela editora Garnier, o livro ${ }^{2}$ recebeu críticas de diferentes segmentos da intelectualidade, sobretudo, do escritor Sílvio Romero. Crítico literário, ensaísta, poeta, filósofo, professor e político. Era membro da Academia Brasileira de Letras, e relevante representante da intelectualidade brasileira. Contudo, também era conhecido pelas polêmicas, pelas críticas ácidas e agressivas. Seus comentários cáusticos recaíram sobre A América Latina: males de origem considerado por Romero uma "panaceia". Chegou a publicar em 1906 uma série de artigos em crítica à obra, resultando em uma compilação denominada A América Latina: Analyse do livro de igual título do Dr. M. Bomfim.

Segundo Aguiar (2000, p. 231), a publicação de A América Latina: males de origem trouxe à tona a organização de um contradiscurso ${ }^{3}$ ao pensamento que vigorava a época entre os setores intelectuais do país. Quando mencionamos o contradiscurso de Bomfim notamos o seu ponto de vista contrário ao paradigma corrente. Neste momento, sua imagem como um intelectual ganhou destaque. Podemos sintetizar como proposta central da obra, a reflexão acerca das questões preconcebidas sobre a formação do povo brasileiro levando em consideração as concepções racistas dominantes à época. Bomfim defendia que os males do atraso brasileiro não era apenas consequência de nossa composição étnica, climática ou de uma hipotética inferioridade de raça devido à 
mestiçagem. Em sua compreensão, para o Brasil se tornar um país democrático e progressista era necessário investir na educação.

As posições assumidas pelo autor angariaram muitas oposições acabando por mobilizar duras críticas a sua obra. No coro "dos descontentes" com a análise de Bomfim, sobressaia Silvio Romero que não poupou adjetivações ao que qualificou como sendo um livro "mal feito, tão falso, tão cheio dos mais grosseiros erros" (Romero apud Sussekind, 2002, p. 609) principalmente ao desacreditar nos "males" que refletiam o atraso de nossa nação: composição étnica, climática ou de uma suposta inferioridade racial.

Até esse momento, as teorias explicativas para o atraso ou o progresso das nações advinham especialmente do positivismo de Comte; do evolucionismo de Spencer; do transformismo de Darwin e da etnologia de Gobineau, dentre outros. Foram estas teorias que, em grande parte, orientaram os discursos e os debates dos setores intelectuais e políticos sobre as possibilidades, ou não, da constituição de uma nação brasileira mais democrática e progressista.

Um dos problemas levantados, à época, referia-se a composição multirracial do Brasil e o obstáculo que representava para a formação da nação. Entre as questões mobilizadoras da intelectualidade estava o desejo em pensar acerca da potencialidade do Brasil se tornar civilizado, para isso perguntava-se sobre as possibilidades de existir uma nação civilizada onde a população fosse predominantemente formada por negros, índios e mestiços. A teoria da desigualdade inata das raças, defendidas por Gobineau e Gustave Le Bon influenciou, sobremaneira os intelectuais brasileiros e, consequentemente $\mathrm{o}$ pensamento social e político do Brasil. Pensadores como Oliveira Martins, Oliveira Viana e Silvio Romero viam na questão racial o grande problema da inferioridade brasileira. Com Silvio Romero, especialmente, as divergências eram mais evidentes, como assinalamos acima e como nos faz ver Santos:

\begin{abstract}
Enquanto Manuel Bomfim (sic) busca evidenciar os problemas da formação da nação, como um "educador" que tende a evidenciar os erros cometidos e a formação que precisa ser orientada através de uma ciência, Silvio Romero, através do papel do intelectual da sociedade, tem em vista dar uma forma à construção da realidade brasileira, e com isso propor o entendimento dos problemas existentes. Neste campo, o "educador da sociedade", Manuel Bomfim buscou as causas do atraso político e social enquanto Silvio Romero, destinado a desempenhar o papel do "intelectual da sociedade" teve em vista "exibir os motivos das originalidades, das particularidades, das diferenciações desse povo no meio de todos os outros" (Santos, 2006, p.67).
\end{abstract}

Silvio Romero considerava ultrajante o "homem do Pedagogium" tecer críticas a autores renomados como Le Bon, censurando principalmente a forma como Manoel Bomfim representava a América Latina, como: vítima da tirania europeia. Romero não poupou adjetivações ao que qualificou como sendo um livro "mal feito, tão falso, tão cheio dos mais grosseiros erros" (Romero apud Sussekind, 2002, p. 609) principalmente ao desacreditar nos "males" que refletiam o atraso de nossa nação: "O autor de "América Latina' suppõe haver atirado com a raiz primária dos alludidos males sociaes e políticos e haver descoberto o remédio adequado a sua extirpação" (Romero, 1906, p. 11).

Em 1906, Romero publicou suas críticas iniciais em Os Annaes uma série de dezesseis artigos sob o título Uma suposta teoria nova da história latino-americana, sendo compilado em um livro no mesmo ano pela Livraria Chardon: A América Latina: analyse 
do livro de igual título do Dr. Bomfim. De início, Romero já questionava a forma de análise científica de Bomfim:

Falsa é a sua base scientifica, falsa a ethnographica, falsa a histórica, falsa a econômica. (...) Não admira, portnto, que falsa seja também a 'causa' a que attribúe os desvios e atropellos da evolução latino-americana, e soffrivelmente inefficaz a 'medicação' que propõe para corrigi-los. (...) Não é o talento do auctor que vai entrar em jogo; é , sim, a pouca segurança de muitas de suas vistas, a erronia das suas doutrinas capitães, a falsidade da mór parte de seus conceitos, a precipitação de suas conclusões, o nenhum valor das fontes em que bebeu (Romero, 1906, p. 11-12).

Bomfim, por sua vez, inovava ao opor-se a este pensamento dominante que atribuía ao fator racial às causas do subdesenvolvimento. Contra essa interpretação dominante propunha a tese do parasitismo social. Enfatizava, então que a lógica da dominação externa imposta pelo colonialismo europeu, combinada com a dominação interna imposta pelas elites teria causado profundos males aos povos latino-americanos. Segundo o autor, o parasitismo resultava em três efeitos: o enfraquecimento do parasitado; as violências que se exerceram sobre eles; e a sua adaptação às condições de vida que lhe eram impostas pelos predadores (Bomfim, 1993, p. 254).

Nesse movimento interpretativo, Bomfim preocupou-se em entender o papel e a influência que a raça identificada como dominante, culta e civilizada exercia sobre as sociedades emergentes. Sua análise assentava-se na idéia de que, até então, poucos estudos haviam sido realizados visando observar "as qualidades positivas dos selvagens e dos negros". Para ele, o essencial era saber qual o valor absoluto dessas raças, em si - a sua capacidade progressista: se são civilizadas ou não. Assim, o que estava em jogo era a definição e a defesa da teoria que afiançava a inferioridade da raça. Neste particular, perguntava sobre o que era esta teoria procurando, ao mesmo tempo, responder. Para ele, "a resposta a estas questões nos dirá que tal teoria não passa de um sofisma abjeto do egoísmo humano, hipocritamente mascarado de ciência barata, e covardemente aplicado à exploração dos fracos pelos fortes" (Bomfim, 1993, p. 267).

Para Manoel Bomfim o que estava na matriz de uma perspectiva de progresso era a educação e não as questões raciais. A educação deveria ser indispensável e como tal constituía-se de intransferível responsabilidade da União, que teoricamente, estaria livre da influência direta das oligarquias políticas estaduais e municipais. Os assuntos educacionais já permeavam a vida do autor, desde sua passagem pela Diretoria de Instrução Pública do Distrito Federal no período de 1895 a 1900, sendo intensificada com a sua entrada no Pedagogium, em 1897, à medida que passava a conhecer mais a fundo os problemas que afetavam o país neste campo, especialmente com relação às graves consequências do analfabetismo.

Somado a esses aspectos, a leitura do relatório intitulado Report of the Commissioner of Education, ${ }^{4}$, elaborado pelo governo dos Estados Unidos da América, de 1893, poderia ser identificado como um elemento a mais que teria levado Bomfim não somente a pensar as questões relacionadas à educação e a instrução popular, mas também de buscar pensar o Brasil no contexto do continente americano. O contato com os dados sobre a situação escolar brasileira, obtidas a partir da leitura do relatório colocou Bomfim diante de um diagnostico alarmante, uma vez que, dentre os trinta países americanos, o Brasil ocupava o terceiro pior índice de escolaridade. Em seu texto Cultura e Educação do povo brasileiro: pela difusão da instrução primária, de 1932, Bomfim teria confessado ter 
sido profunda a impressão que lhe causou a leitura, especialmente pela: "insignificância e pobreza patente dos nossos recursos, que nunca mais pude furtar ao desejo de observar e estudar o problema da instrução popular entre nós. De então para cá só tenho encontrado motivos para maior desconsolo" (Bomfim, 1932, p. 55). A América Latina: males de origem é exemplar dessa preocupação do autor em estudar os problemas da sociedade brasileira e da instrução.

No livro, apesar de o autor conversar intensamente com as questões referentes à sociedade brasileira, seu diálogo se voltava também em compreender o Brasil no contexto dos países da América Latina. Notamos, inclusive, a sua discussão em torno do sentimento latino-americano como um participante significativo do continente americano, e para isto necessitava recuperar seu nacionalismo e, sobretudo, visar o progresso.

Nesta obra Bomfim não objetiva enfatizar a constituição da singularidade do povo, mas explicar historicamente a formação nacional brasileira (e dos latino-americanos) a partir de uma herança comum de dominação e de exploração, pois, para ele, era preciso compreender os motivos pelos quais estes povos se mostravam atrasados social e economicamente. Para Manoel Bomfim, essa relação entre países civilizados e atrasados (desenvolvidos e subdesenvolvidos), tanto do Brasil quanto dos outros países da América Latina seria estabelecida pelas questões econômicas e políticas, e não étnicas ou climáticas. No livro não chega a falar em "povo brasileiro", mas em "povo americano", em posição contrária à doutrina Monroe ${ }^{5}$. Destaca que a organização econômica escravocrata brasileira durante a Colônia e o Império teria colaborado para a constituição de uma nação ignorante e submissa, reduzido a população à ignorância e a abjeção. Para o autor, desde a chegada dos portugueses, a população indígena passou pelo processo violento de escravização que impediu a constituição de uma sociedade com hábito de trabalho pacífico. A introdução dos africanos, não alterou a relação entre senhor e escravo, ou ainda, parasita e parasitário.

Apesar de o autor conversar intensamente com as questões referentes à sociedade brasileira, o seu diálogo se voltava também em compreender o Brasil no contexto dos países da América Latina. Notamos, inclusive, a sua discussão em torno do sentimento latino-americano como um participante significativo do continente americano, e para isto necessitava recuperar seu nacionalismo visando o progresso. Deste modo, para Bomfim, a América Latina e a identidade do latino-americano estavam ameaçadas, uma vez que a "civilização" como "modelo europeu" transbordava sobre ela, e esse "transbordamento" era uma ameaça. Logo, era preciso realizar um esforço consciente e metódico para avançar rumo ao progresso, entrando no movimento em condições de viver "livre entre os livres" (Bomfim, 1993, p. 263). A sua teoria do parasitismo social enfatizava que a lógica da dominação externa imposta pelo colonialismo europeu, combinada com a dominação interna imposta pelas elites teria causado profundos males aos povos latino-americanos. Segundo o autor, o parasitismo resultava em três efeitos: o enfraquecimento do parasitado; as violências que se exerceram sobre eles e a sua adaptação às condições de vida que lhe eram impostas pelos predadores:

Nas próprias sociedades humanas ocorrem freqüentemente fatos análogos. Com as desigualdades sociais e as iniqüidades e vícios das instituições presentes, o regime normal é que uma parte da sociedade viva parasitariamente do trabalho da outra. Todavia, estabeleceu-se um certo equilíbrio, e as classes parasitadas têm a sua sobrevivência garantida no fato de que a extensão dos instintos egoísticos das classes parasitas, o ócio, a devassidão, a degeneração em suma, que se manifestam fatalmente sobre os exploradores, mantêm estes últimos numa situação de relativa inferioridade (Bomfim, 1993, p.123). 
Para Bomfim o Estado seria o principal agente responsável pela caracterização do povo, desde a sua colonização garantindo o máximo de tributos e extorsões através de sua administração política, instituindo uma população desconfiada das autoridades. Dessa forma, o povo americano só pode nascer em:

[...] núcleos de refugos, revéis, escravos fugidos, índios sobreviventes, aos massacres, um ou outro branco desgarrado...e que deram origem a essas populações que, em várias partes do sertão, vêm vivendo sob o regime de um comunismo primitivo - terras de heróis, lavrando algumas nesgas de mandioca, e explorando a caça e a pesca como os selvagens de outrora, sem estímulos, ignorantes, apáticos, sem educação do trabalho, carregando os resíduos de ódios das populações martirizadas (Bomfim, 1993, p. 131).

Deste modo, em seu entendimento, a democracia era possível somente com indivíduos capazes de serem livres e responsáveis, ou seja, naqueles que se permitiam pensar e questionar. Logo, mais que a instrução e ao progresso, a educação elucidaria o povo e, consequentemente, ao país para a real democracia decidida e conduzida igualmente por todos. Movido por esse entendimento, Bomfim apresenta os "males" como se apresentasse um diagnóstico daquelas sociedades adoecidas. Em seu ponto de vista, para entendermos os males antigos era necessário para o conhecimento de suas causas. Desse modo, em seu "Resumo e conclusão" o autor apresentava um caminho para a cura destes males: "A natureza e a origem dos males nos indicarão o remédio ou o remédio delas" (Bomfim, 1993, p. 268), a educação. A educação seria a responsável em levar a nação rumo ao progresso, dentro de uma política democrática e uma sociedade justa.

\section{A Educação popular como "remédio" aos males de Origem do Brasil}

As metrópoles ibéricas parasitavam as colônias que, após a independência, conservaram dentro de si o germe parasita: o senhor parasitava o escravo; os dominantes, os dominados; o Estado parasitava o povo; o capital estrangeiro parasitava a nação. Para sair deste círculo de exploração, propunha uma ampla difusão da educação popular (Carvalho, 1998, p. 205).

A Abolição da escravidão e a Proclamação da República esboçaram mudanças táticas na definição da nação à medida que foram acionadas como condição para o ingresso do país no mundo civilizado. Para Carvalho (1998, p. 248-250), neste processo setores da intelectualidade identificados com a corrente americanista enfatizava a importância de se afirmar a identidade americana do país, visando libertá-lo de sua situação colonial. Para isso, propunham uma "revolução da dignidade econômica". Nessa esteira, Bomfim demonstrava que o Brasil não era uma exceção, pois se associava aos outros países latinoamericanos nesse processo de "exploração". Assim, o fator explicativo do atraso era o parasitismo, sendo a educação popular o caminho para superá-lo.

Em sua compreensão, a transformação do quadro educacional brasileiro romperia com as heranças da colonização, renovando o espírito nacionalista e iniciando um processo de desenvolvimento da nação. Para Bomfim, a ignorância caracterizada pela falta de instrução nulificava o povo e o tornava incapaz de pensar em suas necessidades e acreditar 
num futuro. Era a instrução e a cultura intelectual que provocava o aparecimento das variações individuais e as curiosidades novas. $\mathrm{O}$ progresso era vislumbrado como obra de um pequeno número de inteligências, sendo preciso, todavia, que houvesse "milhões de cérebros" trabalhados, explorados, para que se revelassem essas inteligências de elite, sem esse movimento elas ficariam perdidas e esquecidas na ignorância primitiva. Deste modo, "um cérebro vale pelo uso que dele se faz. É a instrução que, na complexidade da vida, cria essa infinidade de aptidões, onde toda função acha órgão adaptado; quanto mais se revolvem as inteligências, mais probabilidades há de se estimular para caminhos novos" (Bomfim, 1993, p. 277).

\begin{abstract}
A massa geral da população, formada e nutrida por essa cultura intensiva da ignorância e da servidão, não tem estímulos, nem desejos, nem necessidades definidas, acima dos apetites da baixa animalidade; ignora tudo, não sabe trabalhar, não vê beleza, nem interesse no trabalho, nada a convida a isto; inteiramente nula para o progresso, é facilmente aproveitada pela caudilhagem nas más aventuras e assaltos políticos. As classes dirigentes, herdeiras diretas, continuadoras indefectíveis das tradições governamentais, políticas e sociais do Estado-metrópole, parecem incapazes de vencer o peso dessa herança (...) (Ibidem, p. 269).
\end{abstract}

Este ideal seguiu por toda a vida de Manoel Bomfim, e foi defendida por ele intensamente. Acreditava que somente através da educação o povo brasileiro poderia encontrar a verdadeira democracia. Sua dedicação à educação, além do Pedagogium, também se realizou na formação de professores e na produção de livros de leitura para as escolas primárias, a exemplo de Através do Brasil ${ }^{6}$, publicado em 1910, em parceria com Olavo Bilac. Alcançar a infância significava respeitar a individualidade da criança, garantindo-lhe "a plena posse de sua personalidade". Nessa perspectiva, Freitas (2002, p. 362) afirma que Bomfim formulava críticas ao modelo escolar assentada na subordinação da criança a autoridade do professor, herança da cultura ibérica advinda com a colonização, defendendo, por outro lado, a transformação da escola. Ao sinalizar em direção à construção de outra identidade para o escolar, Bomfim defendia que a criança era o agente de sua aprendizagem e o professor o condutor desse processo de autonomia.

Para Freitas, ao formular esta compreensão, Manoel Bomfim redimensionou também o lugar dos professores à medida que o identificava como observadores da infância, como "cientistas voltados para a coleta de dados sobre a realidade infantil" e, portanto, "portadores de uma percepção de civilização que a criança, per se, não poderia adquirir" (Ibidem, p. 364).

Outro aspecto que não passou indiferente a Bomfim foi à falta de empenho da classe política em se concentrar na estruturação de uma sociedade mais justa. Neste sentido, não poupou críticas ao regime republicano e ao fato do regime não ter aprendido com os fatos históricos do passado na compreensão do que seria a raiz do atraso social do Brasil. Para o autor não bastava justificar o atraso com teorias raciais:

Daí, pretende a sociologia da cobiça que somos incapazes, essencialmente inferiores, refratários ao verdadeiro progresso. Estes conceitos só nos devem impressionar pela ameaça que contêm, e não pelo seu mérito científico, nem para que duvidemos do futuro e de nós mesmos. A ciência alegada pelos filósofos do massacre é a ciência adaptada à exploração; a verdadeira, a pura, nos mostra a espécie humana progredindo sempre, em todas as suas variedades - com alternativas, sim, 
devidas à degeneração de grupos e parcialidades, que abandonaram o esforço e a vida (Bomfim, 1993, p. 270).

Para sair desse estágio a proposta de Bomfim era a da expansão da educação, sobretudo da educação pública, que deveria ser uma prioridade uma vez que sofríamos dos males que nos arrastavam para a inferioridade em relação aos povos cultos. Em seu diagnostico a falta de educação para o progresso e o déficit de instrução popular deveriam ser demandas assumidas pela República. Desse modo, procurou relacionar a educação como o meio para se conquistar o progresso, a democracia, a igualdade, e também a liberdade. Para o autor um povo livre, de fato, era um povo instruído, e autônomo em sua forma de pensar sem o domínio da classe dominante: "Ser livre é antes de tudo escapar da escravidão que a ignorância impõe, da escravidão que em nós mesmos reside, e trazer a inteligência a iluminar os atos e a vida" (Bomfim, 1993, p. 272):

Só quando o indivíduo chega a este estado é que ele é livre; é então que ele delibera. E quando a solução se apresenta ao seu espírito, ele deve estar desembaraçado de toda a coação exterior - LIVRE - para cumprir o que a consciência lhe indica. Sem isto, não há atividade possível, nem profícua; o homem não seria homem, senão um anulado, que se conduz à rédea. Sob este aspecto, liberdade se confunde com atividade; toda a coação à liberdade é um entrave à atividade (Ibidem, p. 280).

Podemos notar que A América Latina: males de origem procura ser mais do que dissertativo e científico, busca promover um despertar, apelando em alguns momentos como se as palavras saltassem em gritos soando como um chamamento, sem tom agressivo. Pelo contrário, o autor colocava a educação como uma luz e neste, particular defendia que a função do homem de ciência, do intelectual ou do pensador era o de se emprenhar para realizar mudanças e não esperar soluções apenas no campo do pensamento.

Apesar de estar inserido no contexto da Belle Époque, Manoel Bomfim não se iludiu com a modernidade refletida na arquitetura da cidade, pelo contrário atuou como um crítico da República e das classes dominantes. Ao retornar de Paris com A América Latina: males de origem em mãos e, com ele, a elaboração de um pensamento crítico com relação ao pensamento circulante, procurou reforçar a importância da educação para o desenvolvimento social, econômico, cultural e político do país. Neste sentido, não podemos deixar de considerá-lo, concordando com Freitas, como um intelectual intransigente na defesa da universalização da instrução pública e como cientista social preocupado com o peso e a força da nossa história (2000, p. 360).

Além de intransigente em defesa da universalização da instrução, Bomfim foi engajado a causa da educação, aspecto que se apresenta, sobretudo em A América Latina: males de origem. Podemos dizer que este livro de fato o consolidou como intelectual preocupado com a educação popular e menos em participar de um grupo seleto de intelectuais (Bomfim, 1905, 208).

Das publicações de Manoel Bomfim, podemos dizer que A América Latina: males de origem é a que possui um caráter balizador, sobretudo em relação à consolidação do autor como um intelectual engajado e cientista da educação. Na obra estão delineados os seus preceitos e concepções concernentes à formação do povo brasileiro, tendo como referência um modelo progressista cuja educação eliminaria o atraso e garantiria a soberania nacional (Cockell, 2010, p. 71). 
Consideramos, de fato, a perspectiva do autor ao querer demonstrar através do conhecimento histórico o quanto era necessário compreender o contemporâneo à luz da história. Nessa direção afirma Sussekind (2002, p. 612-613) que houve entre 1880 a 1920 uma reflexão maior por parte de setores da intelectualidade sobre a América Latina e o "papel civilizador do Brasil". Para a autora a estratégia discursiva de Bomfim se associa a esta corrente, contrapondo-se ao pensamento hegemônico à época, uma vez que enfatizava a história, o meio e a cultura como aspectos significativos para se pensar o país e sua organização social. Deste modo, para Bomfim, "a desigualdade hierarquizada das raças humanas não passa de um sofisma abjeto do egoísmo" (Ibidem, p. 614).

Efetivamente, os povos latinos americanos se apresentam, hoje, num estado que mal lhes dá direito a ser considerado povos civilizados. Em quase todos eles, em muitos pontos do Brasil inclusive, a situação é verdadeiramente lastimável. Nações novas deveriam progredir como 100, enquanto as antigas e cultas progridem como 50; só assim lograriam alcançá-las e gozar todos os benefícios que se ligam às civilizações adiantadas. No entanto marcham lentamente, como dez, isto é retardamse, distanciam-se cada vez mais da civilização moderna. E todos sofremos os efeitos desse retardamento. (...) Sofremos todos os males, desvantagens e ônus fatais às sociedades cultas, sem fruirmos quase nenhum dos benefícios com que o progresso tem suavizado a vida humana. Da civilização, só possuímos os encargos: nem paz, nem ordem, nem garantias políticas; nem justiça, nem ciência, nem conforto, nem riqueza; nem trabalho organizado, nem hábito de trabalho livre, muita vez , nem mesmo possibilidade de trabalhar; nem atividade social, instituições de verdadeira solidariedade e cooperação; nem ideais, nem glórias, nem beleza....(Bomfim, 2002, p. 642).

Neste caso, o pensamento de Bomfim encontrava respaldo em intelectuais contemporâneos de outros países latino-americanos, a exemplo do argentino Domingos Sarmiento e do mexicano Antonio Caso (Sussekind, 2002, p. 619). Cioso no poder da instrução como meio de igualar uma sociedade marcada pelo passado colonizador, Bomfim expressava uma forte consciência latino-americana num movimento de escrita que embora sinalizasse em direção as singularidades nacionais não descuidou de olhar o Brasil no contexto continental. Nesse sentido, procurou romper com a "louvação do colonizador", assentando sua argumentação em defesa do nacional e com forte coloração lusófoba. Para Ribeiro, "a lusofobia de Manoel Bomfim era remédio necessário", no Brasil que "(...) falava lisboeta e lia mais autores portugueses que brasileiros, que via nos palcos mais autores lusitanos que nossos, que ensinava a história com base nas falsificações grosseiras bebidas nas obras de Varnhagen, escritas para o trono", (1984, p. 51). Desta forma, foi com este olhar que Bomfim se colocou como um defensor aguerrido da instrução como elemento de progresso para as sociedades americanas, como uma questão de dever e de consciência de todos que partilhassem da crença em "um regime democrático e livre" capaz de "defender a liberdade" e "estabelecer a igualdade" entre os indivíduos.

Em suma, podemos dizer que em A América Latina: males de origem a ênfase se localiza na educação como um meio de se desenvolver a nação rumo ao progresso e à democracia. Para isto, defendia a difusão da educação popular. Para Bomfim, o atraso não podia ser justificado apenas pela teoria das raças, desse modo se contrapõe a esse pensamento atribuindo como causa do atraso "os males", a ignorância com ênfase na teoria do parasitismo social, definida pela lógica da dominação externa imposta pelo 
colonialismo somada à dominação interna das elites. Bomfim diagnosticou os "males" e também o "remédio" para sua cura: a educação, ideia reforçada em outros escritos:

Sofremos, neste momento, uma inferioridade, é verdade, relativamente aos outros povos cultos. É a ignorância, é a falta de preparo e de educação para o progresso - eis a inferioridade efetiva; mas ela é curável, facilmente curável. O remédio está indicado: a necessidade imprescindível de atender-se à instrução popular (Bomfim, 1932, p. 59).

É com este discurso algoz, ausente de neutralidade e por isso mesmo, incômodo que A América Latina: males de origem se tornou uma obra tão significativa na biografia do autor e na história do pensamento social brasileiro. A partir das ideias levantadas no livro publicado em 1905 realizou a tríade formada por $O$ Brasil na América de 1929, O Brasil na História de 1930, O Brasil Nação de 1931. Desse modo, podemos dizer que o livro abriu os horizontes de Bomfim em relação à intelectualidade ganhando notoriedade, e também demarcando o seu engajamento, especialmente concernente à educação.

\section{REFERÊNCIAS}

AGUIAR, Ronaldo Conde. O rebelde esquecido: tempo, vida e obra de Manuel Bomfim. Rio de Janeiro: Topbooks, 2000.

BOMFIM, Manuel. A América Latina: males de origem. Parasitismo Social e evolução. In SANTIAGO, Silviano (Org). Interpretes do Brasil. Volume I. Rio de Janeiro: Nova Aguiar, 2002.

A América Latina: males de origem. Parasitismo Social e evolução. Rio de Janeiro: Garnier, 1905.

. A América Latina: males de origem. Parasitismo Social e evolução. Rio de Janeiro: Topbooks, 1993.

Cultura e Educação do povo brasileiro: pela difusão da instrução primária. Rio de Janeiro: s. ed. 1932.

. O progresso pela instrução. Rio de Janeiro: Instituto Profissional, 1904.

. Pensar e Dizer: estudo do símbolo no pensamento e na linguagem. 2. ed. São Paulo: Casa do Psicólogo, 2006.

BITTENCOURT JÚNIOR, Antonio; CRUZ, José Vieira da (Org). Manoel Bomfim e a América Latina: a dialética entre o passado e o presente. Aracaju: Diário Oficial, 2010.

BOTELHO, André. Aprendizado do Brasil: a nação em busca dos seus portadores sociais. São Paulo, Campinas: Unicamp, 2002.

CAMARA, Sônia; BARROS, Raphael. Por um projeto escolar modelar: a constituição dos grupos escolares no Distrito Federal em finais do século XIX. In: VIDAL, Diana (Org) Grupos Escolares: cultura escolar primária e escolarização da infância no Brasil (18931971). São Paulo: Mercado de Letras, 2006.

CANDIDO, A. Literatura e sociedade. São Paulo: Companhia Editora Nacional, 1972. 
CARVALHO, Marta Maria Chagas de. A Escola e a República e outros ensaios. Bragança Paulista: EDUSF, 2003.

CARVAlHO, José Murilo. Pontos e Bordados. Escritos de história e política. Belo Horizonte: Editora UFMG, 1998.

COCKELL, Marcela. Manoel Bomfim: um intelectual polêmico e engajado na Belle Époque tropical (1898-1914). São Gonçalo, RJ, UERJ-FFP, 2011. Dissertação de mestrado.

FREITAS, Marcos Cezar. Da idéia de estudar a criança no pensamento social brasileiro: a contraface de um paradigma. In: KUHLMANN Jr, Moysés; FREITAS, Marcos Cezar (Orgs) Os intelectuais na História da Infância. São Paulo: Cortez, 2002.

GONDRA, José Gonçalves. O veículo de circulação da Pedagogia Oficial da República: a Revista Pedagógica. In: Revista Brasileira de Estudos Pedagógicos. Brasília, v. 78, n. 188, 189, 190, p. 374-395, jan/dez. 1997. Disponível em: < http://www.rbep.inep.gov.br/index.php/RBEP/article>. Acesso em: 20 fev. 2011.

GONTIJO, Rebeca. Manuel Bomfim (1868-1932) e O Brasil na História. Rio de Janeiro, UFF, 2001. Dissertação de mestrado.

NEEDELL, Jeffrey D. Belle Époque tropical: sociedade e cultura de elite no Rio de Janeiro na virada do século. São Paulo: Companhia das Letras, 1993.

PRIORI, Angelo; CANDELORO, Vanessa D. de Moraes. "Manuel Bomfim: a educação como resposta para 'os males' do Brasil”. In: PRIORI, A.; CANDELORO, V.(Orgs). Dilemas do Desenvolvimento Brasileiro - Séc XIX. Curitiba: Instituto Memória, 2009.

RIBEIRO, Darcy. Manuel Bomfim, antropólogo. In: Revista do Brasil. Ano I, n 2. Rio de Janeiro: Secretaria de Ciência e Cultura, 1984.

ROMERO, Silvio. A América Latina-Analyse do livro de igual título do Dr. Manoel Bomfim. Porto: Livraria Chardon, 1906.

Provocações e Debates: contribuições para o estudo do Brasil Social. Rio de Janeiro: Livraria Chardon, 1910.

SUSSEKIND, Flora. Introdução. In SANTIAGO, Silviano (Org) Interpretes do Brasil. Volume I. Rio de Janeiro: Nova Aguiar, 2002.

\section{NOTAS}

* Professora Adjunta da Graduação e do Programa de Pós-Graduação em Educação da Faculdade de Formação de Professores da Universidade do Estado do Rio de Janeiro. Na instituição coordena o Núcleo Interdisciplinar de Pesquisa em História da Educação e Infância (NIPHEI). Bolsista do Programa Jovem Cientista do Nosso Estado pela FAPERJ.

** Mestre em Educação pelo Programa de Pós-Graduação em Educação Processos Formativos e Desigualdades Sociais da Faculdade de Formação de Professores da Universidade do Estado do Rio de Janeiro (UERJ).

1 Juntamente com Luís Napoleão, Haussmann foi responsável pela reforma da Paris moderna entre 1853 e 1870. Segundo Needell (1993, p. 51) esta reforma urbana consistia em três programas de demolição e construção: substituição das ruas estreitas e congestionadas por bulevares circulares e avenidas mais largas 
que passassem pelo coração da cidade; desmembramento de bairros operários superpovoados e potenciais centros de revolta alegando o controle de epidemias, podendo assim renovar o sistema de esgoto e o acesso a água potável; e por fim embelezar a cidade com a paisagem típica parisiense: grandes monumentos e edifícios imponentes caracterizados pelo estilo de época, o Beaux-Arts - combina influências gregas e romanas com idéias renascentistas, com muitas colunas, flores, estátuas, etc - no Brasil, um exemplo é o Teatro Municipal do Rio de Janeiro, inspirado na Ópera de Paris.

2 Dividido em cinco partes: A Europa e a América Latina; Parasitismo e degeneração; As nações colonizadoras da América do Sul, Efeitos do parasitismo sobre as novas sociedades e As novas sociedades, os títulos dos capítulos do livro A América Latina indiciam o percurso metodológico, mas também o centro argumentativo do autor na relação que estabelece entre a metrópole e a colônia e os efeitos desse processo.

${ }^{3}$ Este contradiscurso de Bomfim pode ser apresentado inicialmente como o discurso crítico divergente do discurso ideológico dominante em relação ao atraso brasileiro, dessa forma foi entendido como uma "contradição". A obra A América Latina: males de origem foi marcante ao tornar pública a posição contrária do autor.

4 Segundo Ronaldo Conde Aguiar (2000, p. 193, nota 221), este relatório foi elaborado pelo governo dos Estados Unidos da América em 1893 e apresenta dados estatísticos relativos ao biênio 1889-1890. Aguiar prognostica que Bomfim deve ter lido esse documento entre 1896 e 1897, já que o menciona no artigo Instrução popular no jornal A República (2 de setembro de 1897) e posteriormente em Cultura e educação do povo brasileiro (193, p. 55).

${ }^{5}$ Os Estados Unidos tinham assumido uma política de isolamento em relação aos assuntos que se passavam na Europa. Os líderes norte-americanos não concordavam com as práticas de intervenção dos europeus e com isso se distanciou da Europa, depois da Santa Aliança em 1815. O presidente, James Monroe, elaborou a chamada Doutrina de Monroe que consistia em desaprovar o direito de intervenção da Santa Aliança nos países da América do Sul, resumida na frase "América para os americanos", tende a ser considerada como o embrião do pan-americanismo, que reforça ainda mais o isolamento norte-americano (Bittencourt Junior; Cunha, 2010, p. 130).

${ }^{6} \mathrm{O}$ livro em forma de narrativa se desenvolve em torno de uma viagem por todo o país realizada por dois meninos gaúchos que estudavam em Recife, Carlos e Alfredo, e Juvêncio um sertanejo que se torna um estimado companheiro dos protagonistas. A aventura destes personagens é retratada como uma longa viagem repleta de paisagens e personagens que refletem a cultura brasileira, e se diferencia pela abordagem não enciclopédica e de vocabulário simples.

Recebido em: $\quad 11 / 01 / 12$

Aprovado em: 06/02/12 